The 49th Annual Conference of the International Association of School Librarianship

The 24th International Forum on Research on School Librarianship

July $12-16,2021$

Natalie Parker

University of North Texas

natalielepski@gmail.com

\title{
Placement of Actor Network Theory in School Library Environment Research
}

\begin{abstract}
Actor Network Theory (ANT) takes on the position that non-human objects which alter the behavior of people with which they share an environment are actors exerting force into the environment. While ANT has been used in education since the late twentieth century, it has not yet seen utilization in school library environments research. As a result, there remains a significant gap in the way school library environments are studied. This literature review seeks to make a case for the importance of including ANT in school library environments research. By taking a closer look at the design and inclusion of specific objects within the school library environment, we can better equip school library spaces for the needs and wants of the students to which the library belongs.
\end{abstract}

Keywords: Actor Network theory, school library, learning environments

\section{Introduction}

In 1996 Wolff-Michael Roth published an article in the 14th volume of Cognition and Instruction. The study contained in the article began with the intention of examining how knowledge diffused throughout a grade 4 and 5 science classroom in a reasonably well-off Canadian school. The study relied heavily on observation and watched these students throughout a unit on engineering. The students were asked to construct bridges in pairs or small groups using engineering principles. One day at the teacher's encouragement in the classroom, a student under the pseudonym of Tom brought a glue gun from home. It is at this moment when Tom brought his glue gun to the class that Roth began to notice something curious change in the dynamic of the classroom. With the aid of his glue gun, Tom suddenly had the ability to approach engineering problems in different ways from his classmates. The struggles that other students had were no match for Tom's mighty hot glue! Classmates began to note the ease at which Tom tackled his problems and his bridge's joint construction. They began to ask Tom to allow them to use his glue gun, to which he said no because his father said that he was the only one allowed to use the glue gun; however, Tom did offer to create and fix joints for his classmates in lieu of allowing them glue gun access. According to Roth's observations, a second student brought a glue gun to class four weeks later, whom Roth named Tim. Similar to Tom, Tim also did not allow others to use his glue gun at first but would provide help to his classmates; later, he not only allowed others to use the device but taught them how to use the 
glue gun. "From then on, the use of glue guns spread quickly, and soon their number rose from four, six, and finally seven" (Roth, 1996, p. 199). The whole class was soon filled with students who had access to a glue gun for their project.

At this moment, when the glue gun became prolific, Roth noted a profound change in the classroom seemingly caused by the introduction of a straightforward tool into widespread use. The students in this classroom began to change their approaches to their projects, beginning to rely on the glue gun for anything and everything, even when it did not suit their needs. But perhaps most profoundly to Roth, the entire classroom environment changed. Student groups changed from being scattered throughout the classroom to two clusters centered around the two outlets available within the classroom to use the glue guns. As a result of the need to be in geographically similar locations, the social dynamic changed with more collaboration and an increase in diverse ideas to problem-solving as more students had access to problem-solving tools and other's brains. The humble glue gun was not a bystander to this shift in the classroom but an integral part in its occurrence.

\section{Introducing Actor Network Theory}

The shift in student organization, problem-solving, and the birth of new ideas would not have happened if not for the introduction and later widespread use of the tool in the environment. Understanding that the tool was not a bystander just there to be used, but a force in changing the environment, one of equal importance as the students wielding it, rests on the theoretical underpinnings employed by Roth in the study: actor network theory (ANT). A theory that has seen a rise in use throughout the world of educational research; used to examine everything from policy and reform to curriculum and the smaller dynamics of the school itself (Fenwick, Edwards, \& Sawchuk, 2011), tracing the small connections that exist between people, the things, and the ideas that surround them creating a deeper understanding of how all interplay to influence the education and learning of students. However, it has not seen the same proliferation within school library research despite it also having a deep interest in the learning environment (Schultz-Jones, Farabough, \& Hoyt, 2015) of the students who are served in an educational setting. Through the introduction of ANT into the more considerable discussion of learning environments research in school libraries, a deeper understanding of how the minute and mundane influence our students, their learning, and the larger school community could be created.

\section{Defining Actor Network Theory}

Actor network theory (ANT) is a sociological theory that emerged out of French sociology in the mid-twentieth century. ANT is most often associated with Bruno Latour. Despite its materialization in the 1980s, there seemed to be no widespread interest in ANT until the early twenty-first century (Fenwick, Edwards, \& Sawchuk, 2011; Wieszaczewska, 2018). One of Latour's most essential works outlining ANT in detail was Reassembling the Social, published in 2005. ANT and Latour take to task what exactly encompasses the social and how people and researchers should view it. Rather than viewing the social as a specified group as is typical of 
modern-day understandings of sociology, a view Latour says takes associations between all things for granted, Latour takes the view that the social is all the connections and associations that exist between actors, defining ANT as the "sociology of associations" (Latour, 2005, p. 9). ANT views all actors in these associations as forming an ephemeral and ever-changing network (Latour, 2005). The network becomes an assemblage of people, materials, ideas, conversations, policy, anything and everything (Fenwick, 2011; Fenwick, Edwards, \& Sawchuk, 2011; Nespor, 2002; Nespor, 2011). Critically distinct to ANT is its approach to non-human materials or objects that exist within this social assemblage, rather than treating the material as less critical or merely a tool of the humans existing within the environment. ANT treats the material or the non-humans within the network with equal weight and importance. The material can be an actor exerting force to alter the environment in the same way as a human (Fenwick, Edwards, \& Sawchuk, 2011). The glue gun in Roth's study altered the structure of the environment with just as much force as the students using the glue gun, altering social relationships and the space itself in a way that would not have occurred without its introduction into the space (1996).

ANT seeks to observe the environment without speaking over it, understanding the ways the complexity of how our connections to people, time, places, ideas, and things alter the state at which we exist. ANT challenges notions a priori research and researchers speaking over those they seek to understand. It resists conventional notions and provides a path to a greater understanding of how the mundane moments and objects, like a glue gun, can drastically shape our world and our actions within it.

\section{Understanding the Distinction of ANTs Approach}

ANT consists of two distinct parts: the actor and how those actors coexist and function within a network. The network within ANT is an ever-changing invisible web connecting all actors in the space, human or non-human, through their associations and interactions with one another (Fenwick, 2011). This point of view on who and what is included in the network contrasts it with social network theory (SNT), limiting itself to examining only humans or large groups of humans. From the perspective of ANT, humans are not the only agents of change within the environment, but so too are all the material objects, and even non-material non-human entities, like policy or cultural norms; all of these make up the environment and how it is shaped over time. ANT understands that all of the things that coexist within the environment bind the environment together even if some only are there momentarily (Fenwick, 2011) as such rejecting the idea "that 'social relations' are independent of the material and natural world" (Whittle \& Spicer, 2008, p. 611).

The social realm is made up of everything that connects with another thing coexisting over time and space-further emphasizing that the non-human is on an equal footing with the humans within the network (Fenwick, Edwards, \& Sawchuk, 2011) that both can affect the influence upon the environment. Therefore both should be considered full-actors with agency capable of producing change (Latour, 2005). 
From this understanding, ANT research seeks to uncover how the human and non-human coexisting in an environment are linked together (Fenwick, 2011). This unwinding of strands of connection can be seen in Roth's study, where he traces the alterations in the classroom environment through the material object of glue guns and the students' actions who use them. Under ANT, if an object or item influences the environment, then that object is an actor within the environment. If a link forms between two or more actors, human or non is immaterial, then a network has formed (Latour, 2005). Understanding how an actor can be recognized becomes the next step.

\section{Defining an Actor}

Within ANT, items are classified in one of two ways, either human or non-human. A non-human can be anything from a paperclip to legislation to writing on a notice board. When deciding if a non-human entity should be classified as an actor existing within a network of human actors, a researcher needs only to answer one assertion - does the object produce an effect in the environment that would be difficult to replicate if that object was no longer present (Mol, 2010)? Does the object afford a unique experience within the environment it is situated (Roth, 1996)? Underneath this basic assertion, Latour asks two more complex questions to answer when identifying a non-human actor: "does it [non-human entity] make a difference in the course of some agent's action or not? Is there some trial that allows someone to detect this difference?" (Latour, 2005, p. 71). Suppose the answer to these questions is "yes," and the non-human entity makes a distinct and detectable difference in how the human agents experience their environment. In that case, the non-human entity is an actor; it has agency, exerts force, and should be given equal importance to the function as a human actor when studying the network of the environment.

Latour provides some examples of how this non-human actor might be discovered, stating that a non-human actor "might authorize, allow, afford, encourage, permit, suggest, influence, block, render possible, forbid, and so on" (2005, p. 72) particular human actions. The Roth study is an excellent example of this phenomenon wherein the introduction of the glue gun allowed the students to alter the construction of their bridges, environment, and both Roth and the classroom teachers could observe social interactions and this change. However, perhaps the most frequent example of a non-human actor found across the literature is a hammer (Latour, 2005; Mol, 2010; Sayes, 2014). If a human actor desired to put a nail into a piece of wood and did not have a hammer, they could probably figure out how to put the nail in, but it might take significantly longer or might simply never do so; however, if they were provided access to a hammer the task more than likely would be accomplished with far more efficiency and accuracy. Therefore a conclusion can be drawn that the hammer is a non-human actor; it exerts force into the environment and alters the actions of the human with which it shares that environment.

\section{The Non-Human in a Human Network}

Once the actors have been established, ANT focuses on establishing the network and associations the actors have with one another. The network is the link, relationship, or 
association that forms between two or more actors. These networks are broken down into four subtypes: 1) necessary for the formulation of society, 2) mediation, 3) moral or political, and 4) part of a larger collective (Sayes, 2014). A non-human actor as necessary for the formulation of society, for example, might be a way to record information like written language or Incan quipu, a non-human actor as a mediator might be the glue gun that facilitates a young child to construct a bridge. For a non-human actor as moral and political association Sayes offers up the example of the seatbelt; it is both considered good behavior to wear a seatbelt as well as being a legal requirement in the United States. Perhaps a timelier example is wearing facemasks in public to prevent the spread of communicable respiratory viruses. Lastly, a non-human actor as part of a larger collective could be one book in a library's larger collection. The school library has the potential to display all of the forms of relationships; its vast collection of information necessary for students to function within the school environment, its computers and tables facilitating student learning, its fines and selection policy acting in a political capacity, and it's the smaller individual books making up one larger collection. Despite the potential for a deep understanding of how all these items interplay in the school library network to influence students, ANT has not truly been used to study the school library network or its actors.

\section{A Place for ANT in School Library Research}

The school library sits within a school, which means, of course, that it exists within the larger educational context of the school and, in a way, should be subjected to the same research considerations as any other part of the school network. ANT in education, primarily science education (Fenwick \& Edwards, 2012; Wieszaczewska, 2018; Wink, 2020), and ANT is relatively new as a whole, not coming about until the 1980s (Fenwick \& Edwards, 2012). Unlike other theories in educational research such as constructivism, ANT offers no explanation of how students learn (Roth, 1996), and indeed that is not the goal. Instead of offering an explanation of how learning occurs, rather it looks at the environment. It adds attempts to show how mundane items, ideas, and things often overlooked shape school and educational relationships. ANT provides additional weight to the importance of how spaces, policy, and curriculum are designed. That the way these items are designed and policy and objects are chosen to fill those spaces, no matter how small, mediate the learning of students, this complexity of small choices with large impacts can be seen in studies by Hamilton (2009) which used actor network theory to investigate the policy impacts of Individual Learning Plans in the UK designed to help students work on targeted needs; Nespor (2011) who used ANT to look at virtual tools and curriculum to help students learn; and of course Roth (1996) who used ANT to show how objects can reshape student learning and organization.

ANT provides "an entry point to better understand the "mundane masses..., assemblages..., materiality..., heterogeneity..., and [the] flows/fluidity" (Fenwick \& Edwards, 2011, p. 12) of the choices we make, the objects we place in our space, the policy we implement, the stories we tell. No matter the time or place where it occurs (including the school library), learning is subject to impact by non-human actors (Edwards \& Clarke, 2011). If an alteration to non-human actors 
occurs within the school library space, like the introduction of a 3D printer into a maker space, then, like the glue gun to Roth's grade 4 and 5 students, so too will change occur to the human actors. However, despite all this, the theory seems to go virtually unused in school library research. A search through all of EBSCOHost with only the "scholarly (peer-reviewed) journals" filter applied the search term: "Actor network theory" AND "school librar*" returned no results with the same parameters Taylor \& Francis Online also returned no results; however, ProQuest did return twenty results. Nevertheless, none actually connected the school library and ANT. This lack of findings from major databases does not mean that ANT has never been used definitively, just that it has not been used frequently enough to be readily found and to the full potential it possesses.

The school library is often thought of as the heart of the school, and it possesses a seemingly unending network of human and non-human actors existing in a temporal flux within the dynamic, ever-changing space. If ANT can be applied to school library environments, research librarians can more effectively learn how the non-human actors within their learning environment alter the human actors cohabitating in the same network. If librarians can better understand the complexity of the mundane, then they stand a better chance of being able to effectively alter the space for a positive outcome through manipulation of the non-human actors. The school library exists to support the educational mission of its larger environment (Bennett, 2015) so understanding the network is vital to organizing the space to fully meet that goal. Perhaps the glue guns can be found.

\section{References}

Bennett, S. (2015). Putting learning into library planning. Libraries and the Academy, 15(2), 215-231.

Edwards, T., \& Clarke, J. (2011). Introduction: Reclaiming and renewing actor network theory for educational research. Educational Philosophy and Theory, 43, 1-14.

Fenwick, T. (2011). Reading educational reform with actor-network theory: Fluid spaces, otherings, and ambivalences. Educational Philosophy and Theory, 43(S1), 114-134. https://doi.org/10.1111/j.1469-5812.2009.00609.x.

Fenwick, T., \& Edwards, R. (2011). Introduction: Reclaiming and renewing actor network theory for educational research. Educational Philosophy and Theory, 1-14. https://doi.org/10.1111/j.1469-5812.2010.00667.x.

Fenwick, T., \& Edwards, R. (2012). Introduction. In T. Fenwick, R. Edwards, T. Fenwick, \& E. Richard (Eds.), Researching education through actor-network theory. John Wiley \& Sons, Incorporated.

Fenwick, T., Edwards, R., \& Sawchuk, P. (2011). Emerging approaches to educational research: Tracing the sociomaterial. Routledge. 
Hamilton, M. (2009). Putting words in their mouths: The alignment of identities with system goals through the use of individual learning plans. British Educational Research, 35(2), 221-242.

Latour, B. (2005). Reassembling the social: An introduction to Actor-Network-Theory. Oxford University Press.

Mol, A. (2010). Actor-network theory: Sensitive terms and enduring tensions. Kölner Zeitschrift Für Soziologie Und Sozialpsychologie Sonderheft, 50, 253-269.

Nespor, J. (2002). Networks and contexts of reform. Journal of Educational Change, 3, 365-382.

Nespor, J. (2011). Devices and educational change. Educational Philosophy and Theory, 43(S1), 15-37. https://doi.org/10.1111/j.1469-5812.2009.00611.x.

Roth, W.-M. (1996). Knowledge diffusion* in a grade 4-5 classroom during a unit on civil engineering: An analysis of classroom community in terms of its changing resources and practices. Cognition and Instruction, 14(2), 179-220.

Sayes, E. (2014). Actor-network theory and methodology: Just what does it mean to say that nonhumans have agency? Social Studies of Science, 44(1), 134-149.

Schultz-Jones, B., Farabough, M., \& Hoyt, R. (2015, June 28-July). Towards consensus on the school library learning environment: A systematic search and review. 2015: IASL Conference Proceedings (Maastricht, Netherlands): The School Library Rocks: Living it, Learning it, Loving it. https://doi.org/10.29173/ias17471.

Whittle, A., \& Spicer, A. (2008). Is actor network theory critique? Organization Studies, 29(4), 611-629. https://doi.org/10.1177/0170840607082223.

Wieszaczewska, A. (2018). The actor-network theory in the context of place-based pedagogy. Journal of Education Culture and Society, 9(2), 167-178.

Wink, D. J. (2020). Chemistry education and the post-constructivist perspective of Bruno Latour. Journal of Chemical Education, 97(12), 4268-4275. 